\section{Sevoflurane vaporizers}

To the Editor:

We would like to report a potential problem with the filler cap on the sevoflurane vaporizers.

The vaporizers on the Ohmeda and North American Drager anesthesia machines are distinctly different except for the fill assembly which has a similar filler cap (Figure). Penlon Ltd, apparently designed and manufactures the agent specific, fill-port assembly for both style vaporizers.

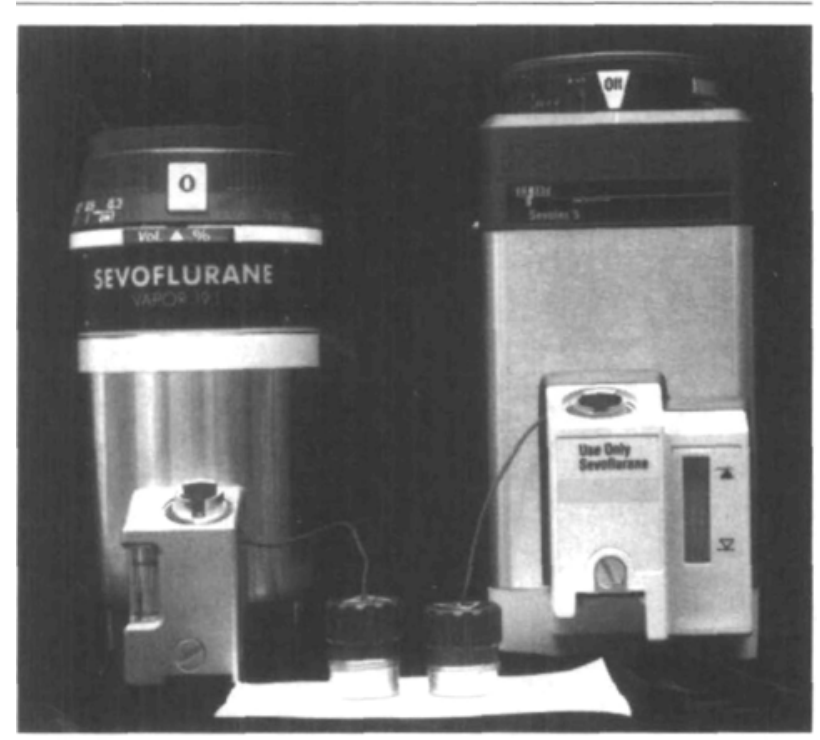

FIGURE

The problem was identified when one of these filler caps was replaced during service. The newly replaced cap did not seal the fill-port tightly resulting in considerable leakage of the vaporizer assembly. This was discovered during the routine machine checkout procedure performed prior to returning the machine into clinical use. Upon further inspection, it was discovered that while both vaporizer style filler caps appear to be the same, the cap available for the Ohmeda style vaporizer is shorter than the one available for the North American Drager style vaporizer. This difference is sufficient to prevent the filler cap from creating a scal, particularly if the shorter Ohmeda cap is used on the North American Drager vaporizer.

The newly designed quick fill adapter is certainly an improvement on agent specificity and the ease to fill the vaporizer. However, the potential hazard from the use of non standardized, similarly threaded design of the new quick fill adapter fill-port cap must be recognized. This demonstrates again the importance of standardization of anesthesia equipment.

Johnson Ngan PhD MD FRCPC

Daniel Cashen RRT

Gary Nichols RRT

Halifax, Nova Scotia

\section{Another use of the "Bair Hugger"}

To the Editor:

We recently provided monitored anesthesia care (MAC) for a 43 yr old (ASA 11), $120 \mathrm{Kg}$ man for a craniotomy. His past history included previous surgery under general anesthesia for resection of an astrocytoma. $\mathrm{He}$ presented with severe seizure disorder mainly due to further growth of the cerebral tumour. He was, rightly, very nervous about the procedure as it was scheduled for MAC. Initially, remifentanil and propofol infusion plus local anesthesia provided adequate operating conditions. All sedation was turned off during the language mapping since the patient needed to be fully alert and cooperative. The patient was, therefore, minimally sedated. Since his face was covered with drapes, he complained of severe claustrophobia and serious lack of air, although $\mathrm{SpO}_{2}$ was $100 \%$. Despite increasing the nasal oxygen to $10 \mathrm{~L} \cdot \mathrm{min}^{-1}$ and providing $15 \mathrm{~L} \cdot \mathrm{min}^{-1}$ of oxygen around his face from the absorber circuit of the Narcomed 2B anesthesia machine, no symptomatic improvement was seen. Further sedation was not indicated since he needed to follow commands during the language mapping. His complaint became so serious that we considered aborting the mapping and inducing general anesthesia.

In desperation we brought in the Polar Air Model 600 (Augustine Medical Corporation, Eden Prairie, MN 55344), a forced air cooler/warmer $\left(10^{\circ} \mathrm{C}\right.$ to $\left.43^{\circ} \mathrm{C}\right)$. We blew cold air $\left(13.5^{\circ} \mathrm{C}\right)$ over his face with immediate relief of his complications, and the language mapping was completed successfully. Surgery was concluded and the patient made an uneventful recovery.

We believe that the use of the Polar Air, in this case, contributed significantly to the success of the monitored anesthesia care for the craniotomy. This, for your readers information.

\author{
Monica Gerstner CST \\ Paul Eckinger MD \\ Patsy Tew RN \\ John G. Brock-Utne MD PhD \\ Stanford, California, USA
}

